\title{
Synthesis and Characterization of Electroless Ni-P/Ni-Mo-P Duplex Coating with Different Thickness Combinations
}

\author{
Gong-Sheng Song ${ }^{1,2} \cdot$ Shuo Sun ${ }^{2} \cdot$ Zhong-Chi Wang $^{1} \cdot$ Cheng-Zhi Luo ${ }^{1} \cdot$ Chun-Xu Pan ${ }^{1,3}$
}

Received: 27 February 2017/Revised: 20 April 2017/Published online: 7 June 2017

(C) The Chinese Society for Metals and Springer-Verlag Berlin Heidelberg 2017

\begin{abstract}
In this work, a novel duplex Ni-P/Ni-Mo-P coating upon the aluminum (Al) substrate was synthesized via an electroless plating, i.e., the binary $\mathrm{Ni}-\mathrm{P}$ coating as a transition layer and the ternary $\mathrm{Ni}-\mathrm{Mo}-\mathrm{P}$ coating on the top. It was found that the duplex coating was of a high hardness, large elastic modulus, low porosity and excellent corrosion resistance. In addition, experimental results revealed that for a total $20 \mu \mathrm{m}$ coating thickness, the duplex coating with a $7 \mu \mathrm{m}$ of the Ni-Mo-P coating exhibited the best corrosion resistance in $0.5 \mathrm{~mol} / \mathrm{L}$ sulfuric acid solution, which was attributed to its compact structure and low porosity. This duplex Ni-P/Ni-Mo-P coating with a thin ternary Ni-Mo-P layer is expected to solve the problem of low deposition rate of ternary alloy coating and thereby may expand applications of $\mathrm{Al}$ and its alloys in the fields of machine manufacture and corrosion environment.
\end{abstract}

\section{KEY WORDS: Electroless plating; Aluminum (Al); Porosity; Ni-P/Ni-Mo-P duplex coating; Corrosion resistance}

\section{Introduction}

Aluminum ( $\mathrm{Al})$ and its alloys is widely used in mechanical industry, power transmission, medical and our daily life, because of their excellent properties, such as low density, good ductility, high specific strength, superior electrical conductivity and thermal conductivity, high reflective and

Available online at http://link.springer.com/journal/40195.

Shuo Sun

sunshuo1979@163.com

Chun-Xu Pan

cxpan@whu.edu.cn

1 School of Physics and Technology, and MOE Key Laboratory of Artificial Micro- and Nano-Structures, Wuhan University, Wuhan 430072, China

2 School of Science, Shenyang University of Technology, Shenyang 110870, China

3 Center for Electron Microscopy, Wuhan University, Wuhan 430072, China oxidation resistance [1-4]. However, the weaknesses involving low surface hardness, inferior corrosion and wear resistances also blocks $\mathrm{Al}$ and $\mathrm{Al}$ alloys' practical industrial applications.

As we all know, electroless binary nickel-phosphorus (Ni-P) plating has been widely applied in industry, due to its advantages of superior corrosion resistance, high surface hardness and wear resistance, simple operation and low cost. It also improves solderability and polishing property of the surface and prolongs the service life [5-8]. Currently, with the development of high industrial requirement, the binary Ni-P alloy cannot meet applications under special conditions, such as specific machine manufacture and the corrosion resistant components in seawater. Therefore, a large number of studies have concentrated upon the electroless ternary alloy, i.e., co-deposition a third metal, including $\mathrm{Zn}, \mathrm{Cu}, \mathrm{Co}, \mathrm{Fe}, \mathrm{Sn}, \mathrm{W}$ and $\mathrm{Mo}$ into the electroless Ni-P coating [9-13]. The resultant ternary alloy exhibits improvements of the coating's physical and chemical properties by adjusting the microstructures and refining the grain size [14]. 
In general, the electroless ternary Ni-Mo-P alloy coating is of higher hardness and corrosion resistance than those of the binary Ni-P coating and can also delay the crystallization temperature [15-17]. It has been demonstrated that the deposition rate of the electroless ternary $\mathrm{Ni}-$ Mo-P alloy coating is lower than that of the binary Ni-P coating, due to the Mo co-deposition. That is to say, when the sodium molybdate concentration is too high, the deposition process will stop, which prevents to form a desired coating [18]. In addition, the Mo-P co-deposition also increases the hardness and internal stress concentration of the coating, which makes the coating more brittle and prone to cracking and stripping when the coating reaches a large thickness [19].

Recently, most researches have focused mainly on certain constant thickness of duplex coatings, such as Ni-P/ Ni-Mo-P [20], Ni-P/Ni-W-P [21], Ni-P/Ni-B [22] and $\mathrm{Ni}-\mathrm{P}-\mathrm{ZrO}_{2} / \mathrm{Ni}-\mathrm{P}$ [23]. However, a lot of electroless $\mathrm{Ni}-$ based coatings present variations of morphologies and chemical compositions with depth of the coating, and it is even more probable that the chemistry of Ni-Mo-P varies with the deposition time. And in addition, the generation of the internal stress varies with many factors, including deposition temperature, deposition time and during electroless process [24].

In this work, we synthesized the electroless $\mathrm{Ni}-\mathrm{P} / \mathrm{Ni}-$ Mo-P duplex coating on the $\mathrm{Al}$ surface, i.e., applying an electroless binary $\mathrm{Ni}-\mathrm{P}$ coating as a transition layer and plating a ternary Ni-Mo-P coating on the top. And the effects of different thickness combinations of the Ni-P and Ni-Mo-P coatings on the coating's surface morphology, porosity, corrosion resistance and mechanical property were investigated. It was found that this duplex coating exhibited excellent characters, such as uniform and compact surface, low porosity, good corrosion resistance and high mechanical property. This duplex coating with a thin ternary Ni-Mo-P coating is expected to solve the problem of low deposition rate of ternary alloy coating, thereby expanding applications of $\mathrm{Al}$ and its alloys in the fields of machine manufacture and corrosion environment.

\section{Experimental}

Commercial pure aluminum $(\mathrm{Al})$ sheets with $25 \mathrm{~mm} \times$ $10 \mathrm{~mm} \times 0.1 \mathrm{~mm}$ in size were used as the substrate. Table 1 lists the major elements of the $\mathrm{Al}$ substrate. The $\mathrm{Al}$

Table 1 Chemical compositions of commercial pure aluminum ( $\mathrm{Al})$ substrate (wt $\%)$

\begin{tabular}{lllll}
\hline $\mathrm{Si}$ & $\mathrm{Fe}$ & $\mathrm{Cu}$ & $\mathrm{N}$ & $\mathrm{Al}$ \\
\hline 0.15 & 0.015 & 0.015 & 0.005 & $\mathrm{Bal}$. \\
\hline
\end{tabular}

sheets were totally subjected to the processing steps as follows: cleaning $\rightarrow$ alkaline degreasing $\rightarrow$ acid pickling $\rightarrow$ electroless nickel pre-plating $\rightarrow$ electroless binary $\mathrm{Ni}-\mathrm{P}$ plating $\rightarrow$ electroless ternary $\mathrm{Ni}-\mathrm{Mo}-\mathrm{P}$ plating $\rightarrow$ rinsing $\rightarrow$ properties tests. Table 2 lists the detailed parameters for each step.

The morphologies, crystallization and chemical compositions of the samples were characterized by using a scanning electron microscope (SEM) (S-4800, Hitachi, Japan, and SIRON, FEI, the Netherlands) equipped with an energy-dispersive X-ray spectroscopy (EDS), X-ray diffraction spectrometer (XRD, D8 Advance, Bruker AXS, Germany) with $\mathrm{Cu} K_{\alpha}$ radiation, X-ray photoelectron spectroscope (XPS, ESCALAB 250Xi, Thermo Fisher, USA) with $\mathrm{Al} K_{\alpha}$ radiation of $1486.6 \mathrm{eV}$ as the excitation source. The hardness and elastic modulus of the samples were measured by using an instrumental nanoindenter (Agilent G200 Nanoindenter, Agilent Technologies, USA). The CSM (continuous stiffness measurement) standard hardness and modulus test program were used, in which the harmonic depth and frequency were $2 \mathrm{~nm}$ and $45 \mathrm{~Hz}$, respectively. The maximum indentation depth was $2000 \mathrm{~nm}$. For each sample, ten points were tested for getting an average value.

The porosity of the coatings was measured according to the Chinese Light Industry Standard QB/T3823-1999, i.e., a filter paper method. The solution compositions consisted $3.5 \mathrm{~g} / \mathrm{L}$ aluminon and $150 \mathrm{~g} / \mathrm{L}$ sodium chloride. The soak time was $10 \mathrm{~min}$ for each sample. The measurement was carried out according to the processes: (1) put a glass plate with square grids (square covers an area of $1 \mathrm{~cm}^{2}$ ) on the filter paper with the flecked pores; (2) count the number of the spots within a square grid; and (3) calculate the data of porosity (number of spots $/ \mathrm{cm}^{2}$ ). The porosity calculation was made according to the rules: (1) when the spot diameter was less than $1 \mathrm{~mm}$, one spot was regarded as one pore; (2) when the spot diameter was in a range of 1-3 $\mathrm{mm}$, one spot was regarded as three pores; (3) when the spot diameter was in a range of 3-5 mm, one sport was regarded as ten pores; and (4) the final result was determined by the mean value of three measurements.

The corrosion resistance of the coatings was performed by using an electrochemical workstation (CHI604D, Chenhua Instrument Company, China) in $0.5 \mathrm{~mol} / \mathrm{L} \mathrm{H}_{2} \mathrm{SO}_{4}$ solution under the room temperature. A conventional threeelectrode setup was used, i.e., the sample served as a working electrode, a saturated calomel electrode (SCE) as a reference electrode and a platinum net as an auxiliary electrode. For each sample, the open-circuit potential (OCP) was first measured for half hour. The polarization curve was obtained at a constant scan rate of $0.5 \mathrm{mV} / \mathrm{s}$, and the voltage range was approximately $\pm 150 \mathrm{mV}$ versus the OCP. 
Table 2 Parameters for every process

\begin{tabular}{|c|c|c|c|c|}
\hline Process & Solution composition & $\mathrm{pH}$ & Temperature $\left({ }^{\circ} \mathrm{C}\right)$ & Time (min) \\
\hline Cleaning & Anhydrous ethanol & & 25 & 1 \\
\hline Alkaline degreasing & $20 \mathrm{wt} \%$ sodium hydroxide solution & & 40 & 0.3 \\
\hline Acid pickling & 20 vol\% nitric acid & & 25 & 3 \\
\hline Electroless Ni pre-plating & $\begin{array}{l}13 \mathrm{~g} / \mathrm{L} \text { nickel sulfate } 30 \mathrm{~g} / \mathrm{L} \text { sodium hypophosphite } \\
40 \mathrm{~g} / \mathrm{L} \text { sodium citrate } \\
30 \mathrm{~g} / \mathrm{L} \text { ammonium chloride }\end{array}$ & $9-10$ & 50 & 5 \\
\hline Electroless binary $\mathrm{Ni}-\mathrm{P}$ plating & $\begin{array}{l}27 \mathrm{~g} / \mathrm{L} \text { nickel sulfate } \\
30 \mathrm{~g} / \mathrm{L} \text { sodium hypophosphite } \\
20 \mathrm{~g} / \mathrm{L} \text { sodium acetate } \\
1.2 \mathrm{~g} / \mathrm{L} \text { sodium citrate } \\
31 \mathrm{~mL} / \mathrm{L} \text { lactic acid } \\
3.7 \mathrm{~mL} / \mathrm{L} \text { propionic acid } \\
5 \mathrm{mg} / \mathrm{L} \text { copper sulfate } \\
5 \mathrm{mg} / \mathrm{L} \text { sodium thiosulfate }\end{array}$ & 5 & $91 \pm 1$ & 60 \\
\hline Electroless ternary $\mathrm{Ni}-\mathrm{Mo}-\mathrm{P}$ plating & $\begin{array}{l}31 \mathrm{~g} / \mathrm{L} \text { nickel sulfate } \\
31 \mathrm{~g} / \mathrm{L} \text { sodium hypophosphite } \\
20 \mathrm{~g} / \mathrm{L} \text { sodium pyrophosphate } \\
40 \mathrm{~g} / \mathrm{L} \text { ammonium sulfate } \\
0.8 \mathrm{~g} / \mathrm{L} \text { sodium molybdate } \\
10 \mathrm{ml} / \mathrm{L} \text { triethanol amine } \\
1 \mathrm{mg} / \mathrm{L} \text { thiourea } \\
0.05 \mathrm{~g} / \mathrm{L} \text { sodium dodecyl sulfate } \\
1 \mathrm{~g} / \mathrm{L} \text { saccharin }\end{array}$ & 9 & $70 \pm 1$ & 60 \\
\hline
\end{tabular}

\section{Result and Discussion}

In order to obtain a desired electroless $\mathrm{Ni}-\mathrm{P}$ or $\mathrm{Ni}-\mathrm{Mo}-\mathrm{P}$ coating on the $\mathrm{Al}$ substrate, in our previous work, we introduced a novel environment friendly formulation of the electroless Ni pre-plating (also called nickel immersion) solution. That was, alkaline etch and acid pickling were used to remove thoroughly the alumina layer, and the pre-plating nickel solution contained $13 \mathrm{~g} / \mathrm{L}$ nickel sulfate, $30 \mathrm{~g} / \mathrm{L}$ sodium hypophosphite, $40 \mathrm{~g} / \mathrm{L}$ sodium citrate, $30 \mathrm{~g} / \mathrm{L}$ ammonium chloride. Experimental results revealed that 5-min pretreatment provided a homogeneous pre-plating layer on the $\mathrm{Al}$ surface, which was considered to be the best condition for the subsequent plating. The effect of the preplating time on the morphologies of the binary Ni-P and ternary $\mathrm{Ni}-\mathrm{Mo}-\mathrm{P}$ coatings, and bonding strength between the coating and substrate were also studied [25].

Figure 1 shows the SEM morphologies of the electroless binary Ni-P coating and the duplex Ni-P/Ni-Mo-P coating. We can see that there were many holes on the Ni-P coating and no hole on the duplex coating. The particles size of the Ni-P coating was smaller than that of the duplex coating, which was caused by co-deposition of element Mo.
Figure 2 illustrates the EDS chemical composition profiles of a single Ni-P coating and the $14+6$ Mo duplex coating, respectively. $3.63 \mathrm{wt} \%$ phosphorus (P) content was measured from the single binary Ni-P coating, which belonged to a kind of low P coating. In the surface of the duplex coating, the elements of Mo and $\mathrm{P}$ were detected with data $1.03 \mathrm{wt} \% \mathrm{P}$ and $2.05 \mathrm{wt} \% \mathrm{Mo}$, which showed that the upper layer was the ternary Ni-Mo-P coating. This result was also proved by element mapping analysis of the duplex coating, as shown in Fig. 3.

Figure 4 shows the XRD patterns of the electroless Ni-P alloys and the duplex Ni-P/Ni-Mo-P coatings. According to the patterns, it is evident that only a single peak was detected for the Ni-P coating, while extra two weak peaks were observed for the duplex coating. These revealed that the Ni-P coatings had an amorphous-like structure, and the duplex coating showed a more crystalline nature. In general, $\mathrm{P}$ content in the coating determines the crystal structure of the electroless Ni-P coating. That is to say, high $\mathrm{P}$ content in the coating leads to an amorphous structure, while low P content shows a crystalline structure. Therefore, if a third element (such as Mo) is added to the coating, it will influence the $\mathrm{P}$ content and causes changes of the coating microstructures. Many reports have indicated that 

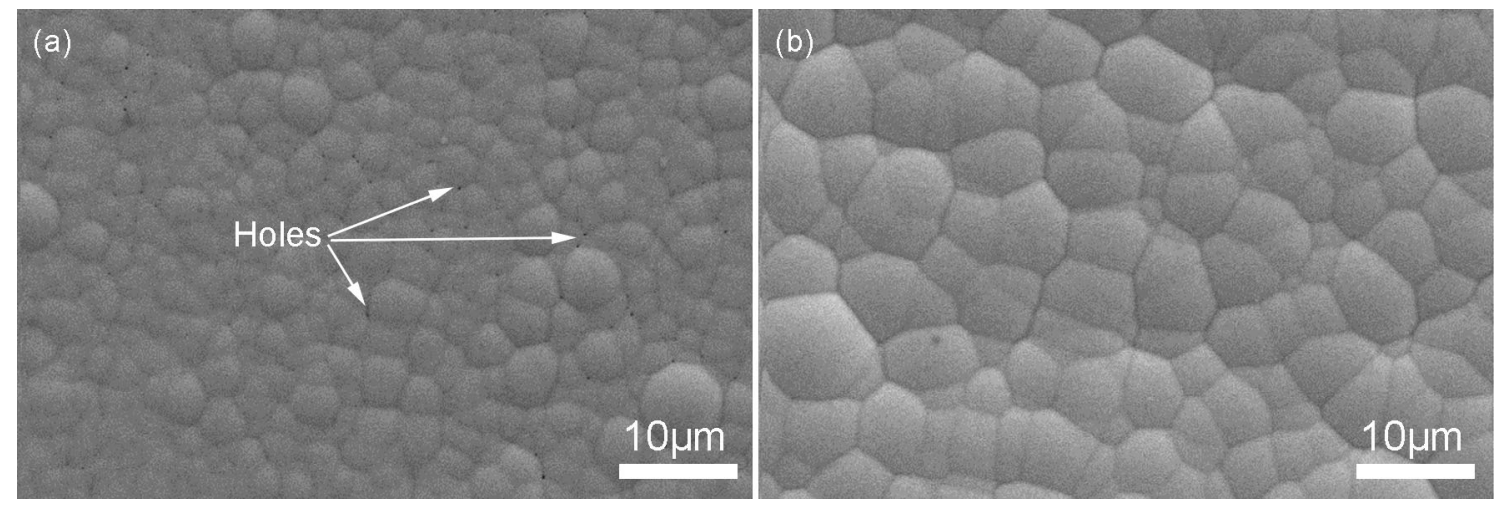

Fig. 1 SEM images of a Ni-P coating, b Ni-P/Ni-Mo-P duplex coating
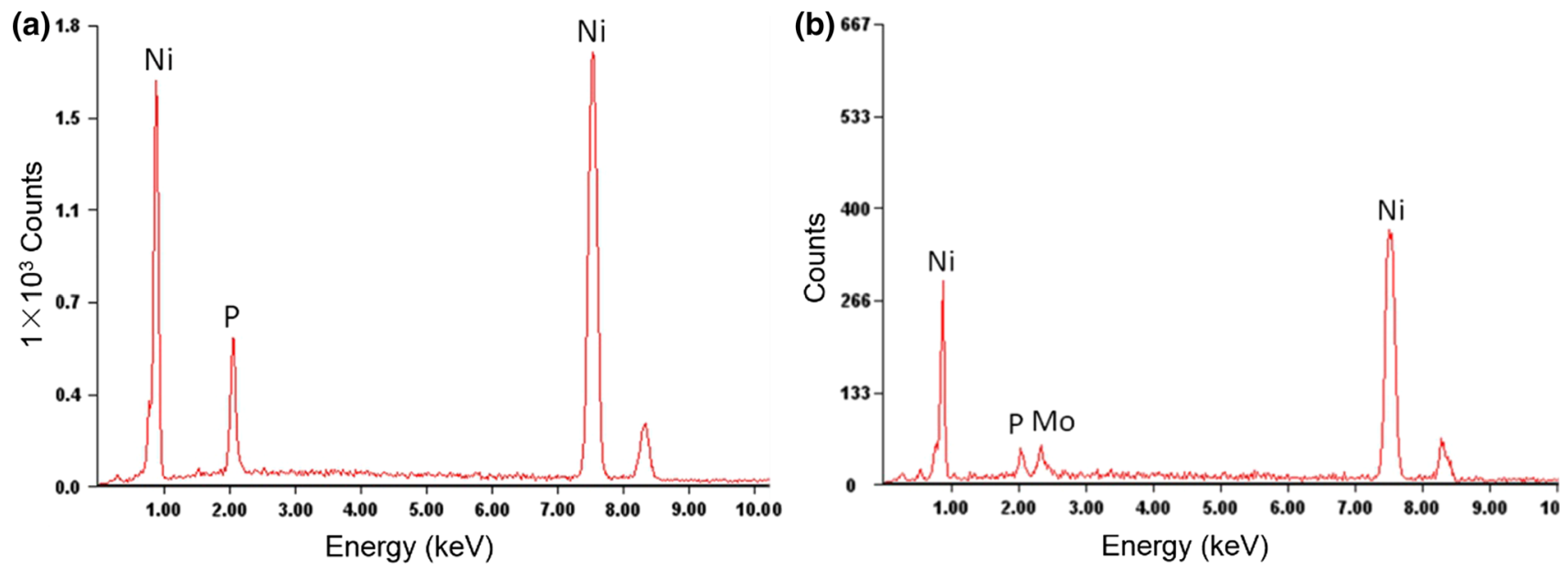

Fig. 2 EDS analysis of a Ni-P coating, b Ni-P/Ni-Mo-P duplex coating

the Mo content exhibited a negative correlation with the $\mathrm{P}$ content in the coating $[26,27]$. In the present work, the outer Ni-Mo-P coating contained low P (about 1.03 wt\%) and consisted of the crystalline and microcrystalline nickel, which indicated that the number of $\mathrm{P}$ atoms was not sufficient to distort the Ni lattice to an extent to form the $\mathrm{Ni}$ amorphous. The diffraction peak was corresponded to the (111) plane of a face centered cubic phase of nickel [28].

Figure 5 shows the XPS spectra of the Ni-P coating and the duplex coating. The survey scan suggested that the duplex coating contained elements of $\mathrm{Ni}, \mathrm{Mo}, \mathrm{P}$ and $\mathrm{O}$. C element was also detected on the surface of the outer $\mathrm{Ni}-$ Mo-P coating, possibly due to surface contamination by atmospheric hydrocarbon during storage. The constituent elements exhibited in various states. The Ni $2 p$ spectrum in Fig. $5 \mathrm{~b}$ indicated that $\mathrm{Ni}$ existed as element $\mathrm{Ni}$ and nickel hydroxide, corresponding to the peaks at binding energies of 852.6 and $855.8 \mathrm{eV}$, respectively. The Mo $3 d$ spectrum in Fig. 5c showed different species of Mo in the coating. The peaks at 227.7 and $230.8 \mathrm{eV}$ correspond to element $\mathrm{Mo}$, and those at $235.3 \mathrm{eV}$ indicated the presence of $\mathrm{MoO}_{x}$, respectively. The peaks of element $\mathrm{P}$ appeared at 129.3 and
$130.2 \mathrm{eV}$, as shown in Fig. 5d, and peak at $133.5 \mathrm{eV}$ was due to existence of $\mathrm{PO}_{x}$ [29].

Figure 6 shows the SEM images of the surfaces and cross sections of the duplex Ni-P/Ni-Mo-P coating with different thicknesses of the outer Ni-Mo-P coating (total thickness was $20 \mu \mathrm{m}$ ). The results showed that with the increase in thickness of the Ni-Mo-P coating, the surface morphologies were changed significantly, i.e., from poriferous to compact and cracking. That is to say: (1) when the coating thickness was less than $7 \mu \mathrm{m}$, the surface was poriferous; (2) when the coating thickness reached $7 \mu \mathrm{m}$, the compact structure was formed; (3) at the arrange of $10-13 \mu \mathrm{m}$, the surface was somewhat uneven, because of the decrease in stability of the plating solution and effect of the impurity substances within the plating solution. The large cellular size in Fig. 6d was attributed to the aging of bath solution and consumption of the complex agent, i.e., production and agglomeration of impurity during electroless process and the weakened complexion increased the grain growth rate and therefore resulted in a higher growth rate than the nucleation rate. At last, the large cellular size was formed; (4) when the coating thickness was large 

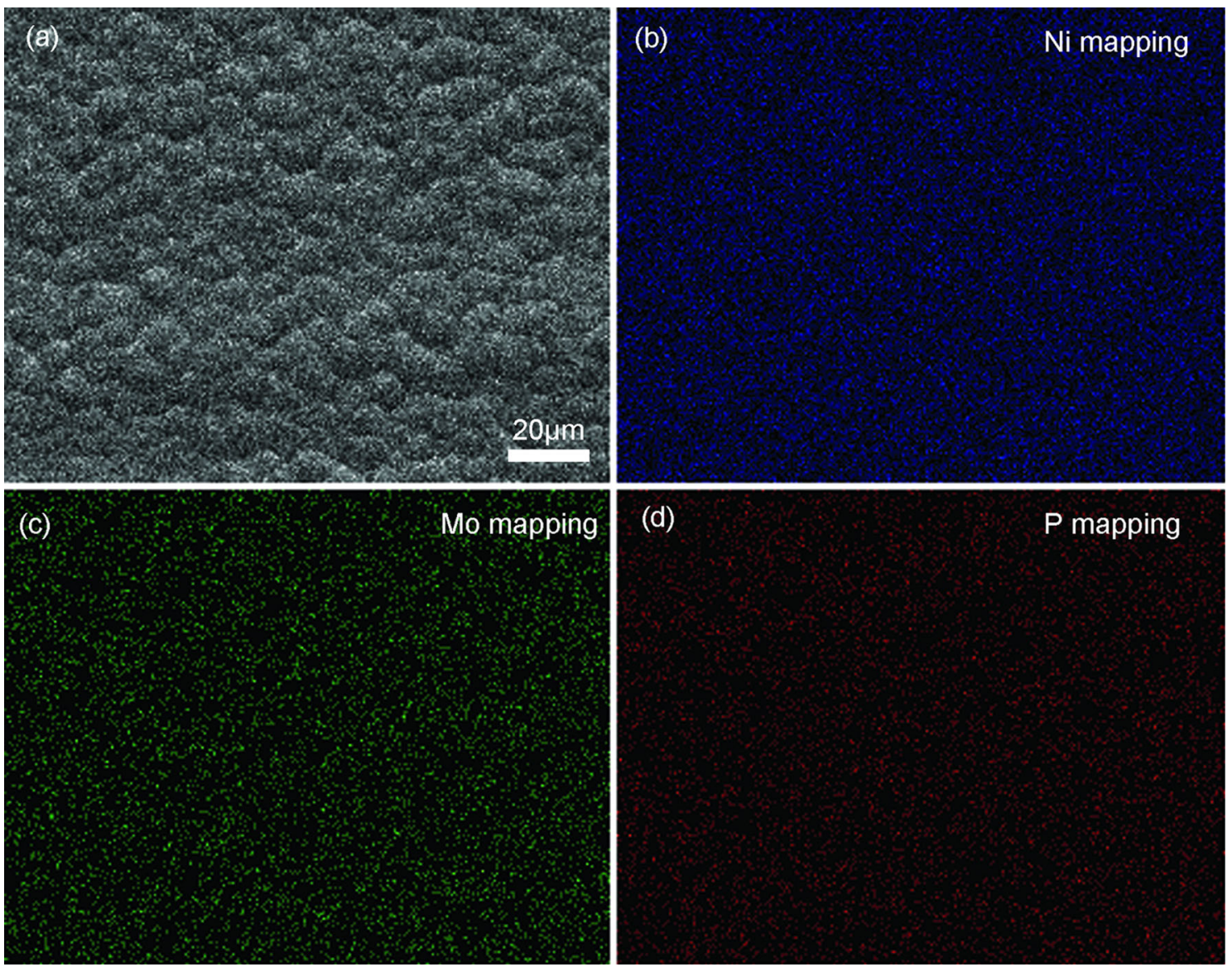

Fig. 3 EDS elemental mapping analysis of Ni-P/Ni-Mo-P duplex coating: a SEM image; b Ni element; c Mo element; d P element

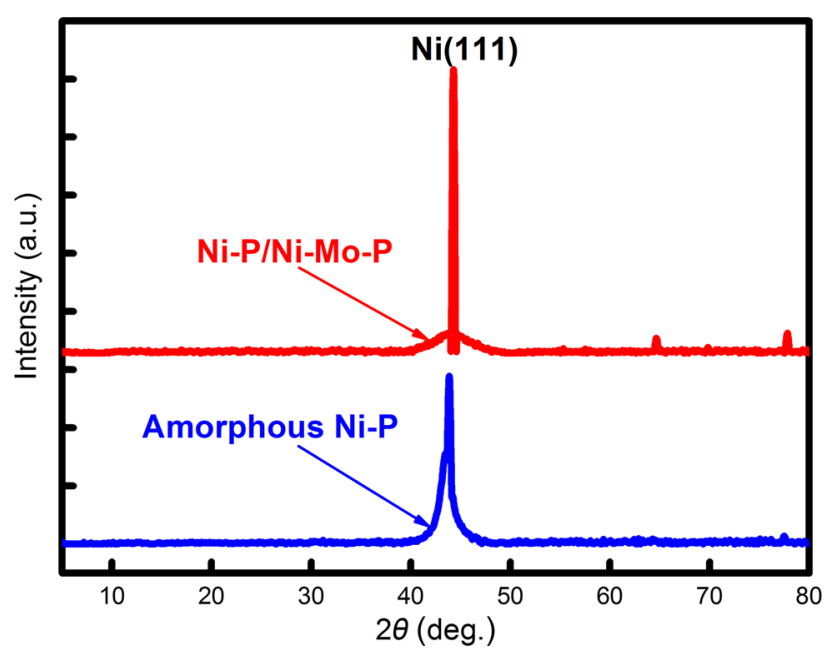

Fig. 4 XRD patterns of Ni-P coating and Ni-P/Ni-Mo-P duplex coating with $7 \mu \mathrm{m}$ of Ni-Mo-P coating

enough and reached $17 \mu \mathrm{m}$, the cracks were observed in the coating, due to a large internal stress concentration in the coating [30]. From the cross-section morphology, as shown in Fig. 6f, favorable homogeneity and approximate thickness of the duplex coating were observed distinctly, which demonstrated a good adhesion strength at both the interface between the $\mathrm{Al}$ substrate and the $\mathrm{Ni}-\mathrm{P}$ coating, and between the Ni-P coating and the Ni-Mo-P coating.

It has been known that, during electroless plating, the formation of porous coating is because of the $\mathrm{H}^{+}$aggregation adjacent to cathode and adsorption at the substrate. Generally, a small amount of hydrogen will remained with the coating and results in the pore formation. In addition, when the coating is too thin, there are not sufficient particles to cover in the surface and also form gaps in the surface. Obviously, once the corrosive medium seeps into the coating via the pores and gaps, a galvanic cell will be generated and accelerated the corrosion process. In a word, the size and the number of the porosity in the coating affect seriously on corrosion resistance of the coatings.

Figure 7a shows the porosity variations of the Ni-P coating and the duplex Ni-P/Ni-Mo-P coating with different thicknesses of the Ni-Mo-P coating. Clearly, when the Ni-Mo-P coating thickness was less than $7 \mu \mathrm{m}$, a number of pores were observed in the duplex coating. However, for the thickness in a range of 7-10 $\mu \mathrm{m}$, no pores were observed, which was attributed to the compact structure of the duplex coating. When the thickness 
(a)
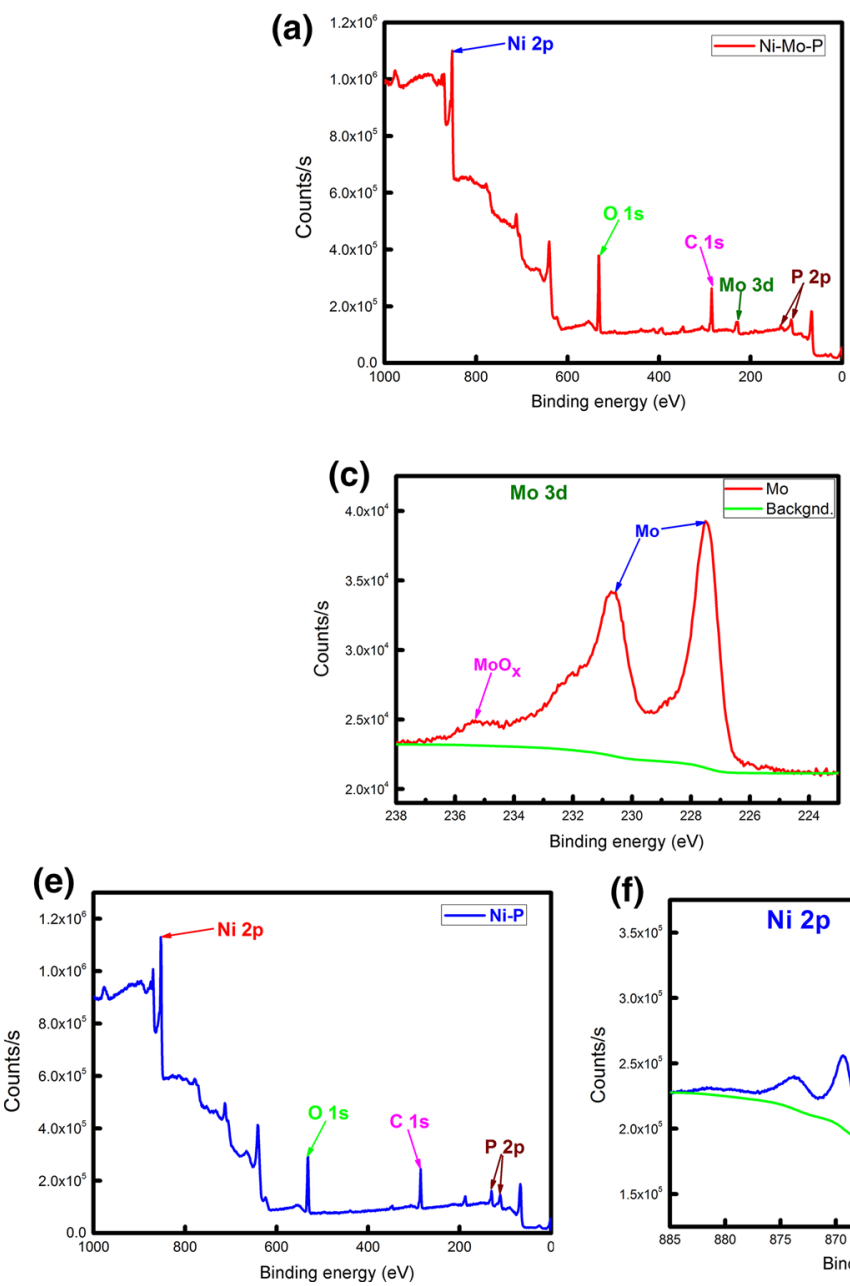
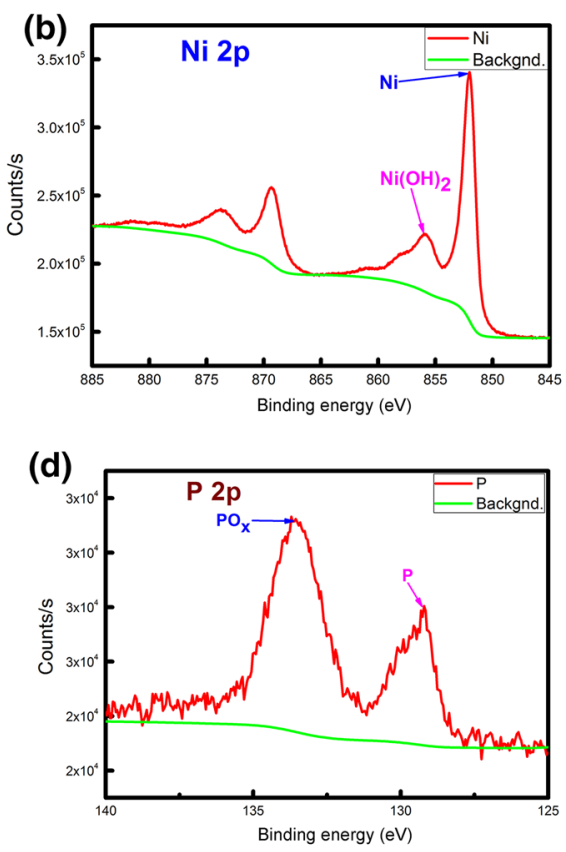
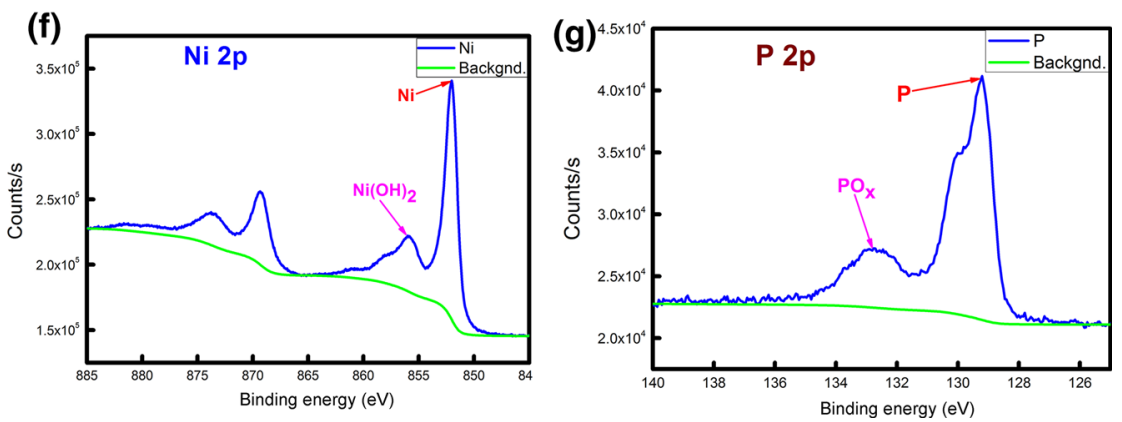

Fig. 5 XPS spectra of Ni-P/Ni-Mo-P duplex coating a-d (a full scope spectrum, b Ni $2 p$ spectrum, c Mo $3 d$ spectrum, d P $2 p$ spectrum) and $\mathrm{Ni}-\mathrm{P}$ coating e-f (e full scope spectrum, $\mathbf{f}$ Ni $2 p$ spectrum, $\mathbf{g}$ P $2 p$ spectrum)

exceeded $17 \mu \mathrm{m}$, the coating began to strip from the substrate. For the binary Ni-P coating, even the thickness reached $20 \mu \mathrm{m}$, only few pores were observed on the surface.

Further, we studied the relationship between the thickness of the Ni-Mo-P coating and corrosion resistance of the duplex coating. Figure $7 \mathrm{~b}$ and Table 3 give the potentiodynamic polarization curves and its fitting results of the duplex coatings with different thicknesses in a $0.5 \mathrm{~mol} / \mathrm{L}$ sulfuric acid solution, respectively. It was revealed that, when the Ni-Mo-P coating thickness was around $7 \mu \mathrm{m}$, there existed the most positive corrosion potential and the minimum corrosion current, which demonstrated the best corrosion resistance of the duplex coatings, because of only few pores in the coating surface. Therefore, the duplex coating effectively improved the porosity and corrosion resistance of the binary $\mathrm{Ni}-\mathrm{P}$ coating.

Figure 8 presents typical nanoindentation load-displacement curves of the coatings for comparison with the
Al substrate. Obviously, the coatings have a significant influence on the nanoindentation property, i.e., for the same $2000 \mathrm{~nm}$ penetration depth, the maximum load $\left(P_{\max }\right)$ was $39 \mathrm{mN}$ for the Al substrate, while the $P_{\max }$ increased to 400 $\mathrm{mN}$ and $491 \mathrm{mN}$ for the Ni-P and Ni-Mo-P coatings, respectively. According to these curves, the hardness $(H)$ and elastic modulus $(E)$ of the coatings could be calculated from the following equations by using the data including $P_{\max }$, initial slope (or indentation stiffness) $(S)$ of the unloading curve, and the projected contact area $\left(A_{\mathrm{c}}\right)$ [31]:

$H=\frac{P_{\max }}{A_{\mathrm{c}}}$,

where $A_{\mathrm{c}}$ can be further calculated as a function of the contact penetration depth $\left(h_{\mathrm{c}}\right)$. And $h_{\mathrm{c}}$ is related to the deformation behavior of the materials and the shape of the indenter. Therefore, $h_{\mathrm{c}}$ is estimated as:

$h_{\mathrm{c}}=h_{\max }-\frac{\varepsilon P_{\max }}{S}$, 

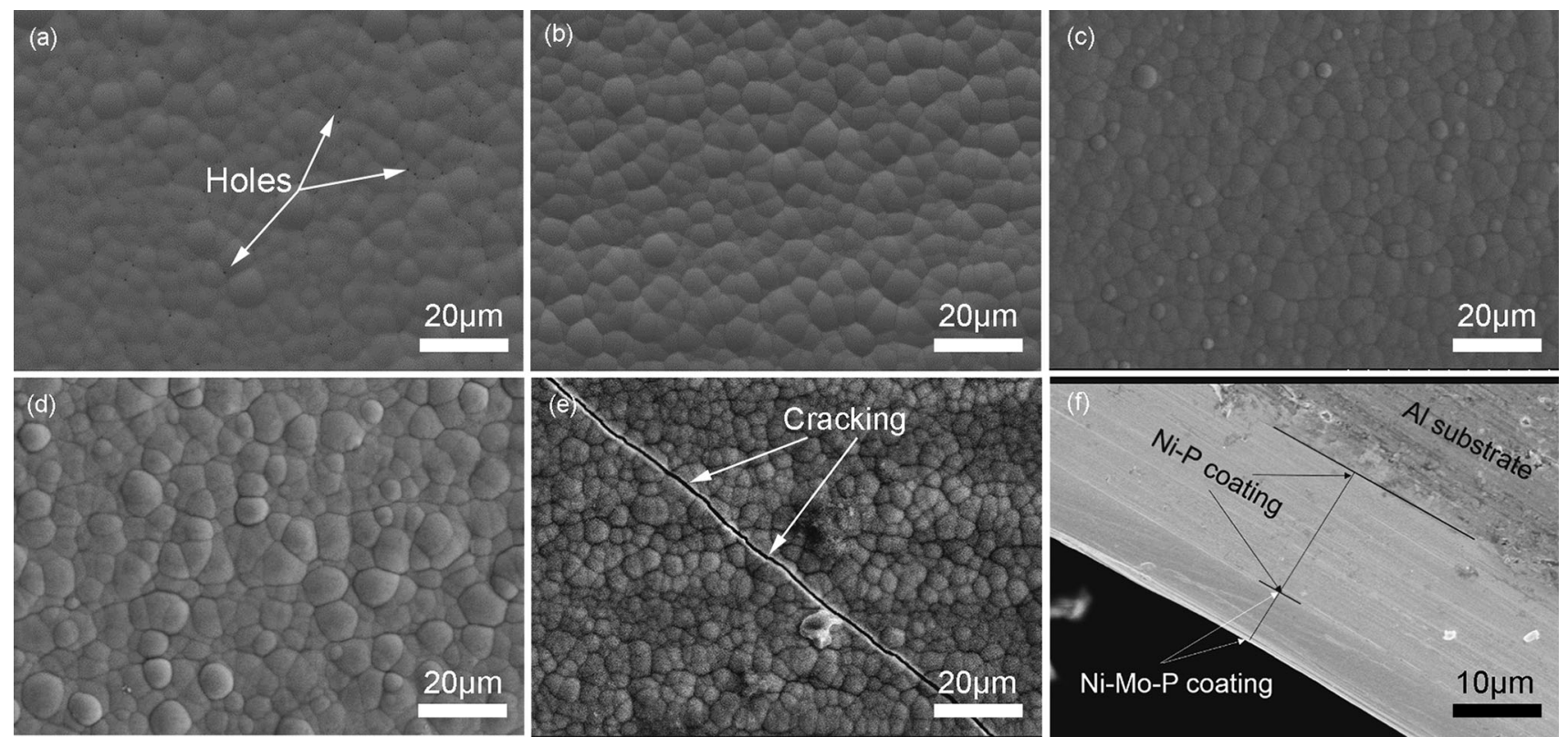

Fig. 6 SEM morphologies of duplex Ni-P/Ni-Mo-P coating with different thicknesses of outer Ni-Mo-P coating: a $4 \mu \mathrm{m}$, b $7 \mu \mathrm{m}, \mathbf{c} 10 \mu \mathrm{m}$, d $13 \mu \mathrm{m}$, e $17 \mu \mathrm{m}$, f cross-section morphology of Ni-Mo-P coating of $7 \mu \mathrm{m}$ (total thickness was $20 \mu \mathrm{m}$ )
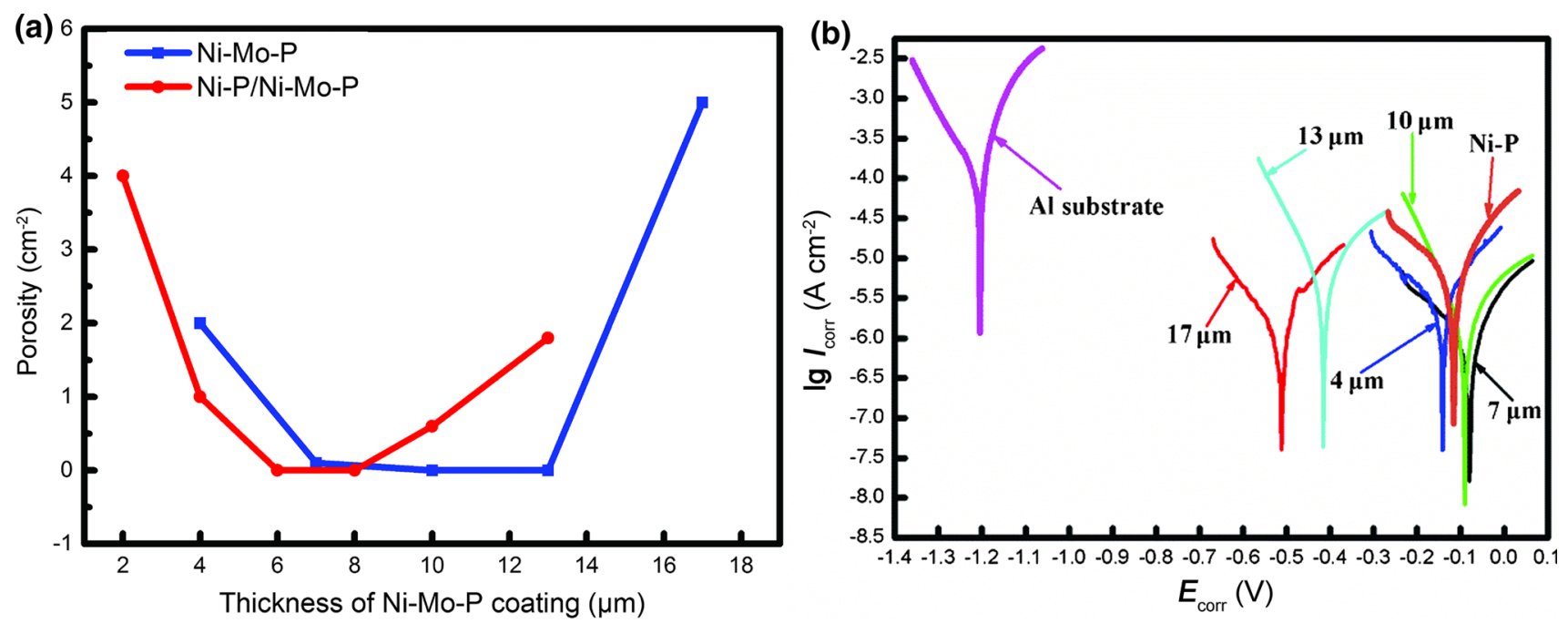

Fig. 7 Porosity of Ni-P coating and Ni-P/Ni-Mo-P duplex coatings a and potentiodynamic polarization curves of bare Al, Ni-P coating and $\mathrm{Ni}-\mathrm{P} / \mathrm{Ni}-\mathrm{Mo}-\mathrm{P}$ duplex coatings with different thicknesses of outer $\mathrm{Ni}-\mathrm{Mo}-\mathrm{P}$ coating in $0.5 \mathrm{~mol} / \mathrm{L} \mathrm{H}_{2} \mathrm{SO}_{4}$ solution (total thickness was $20 \mu$ m; $E_{\text {corr }}$ : corrosion potential; $I_{\text {corr }}$ : corrosion current density) b

where $\varepsilon$ is a constant that depends on the geometry of the indenter. For the Berkovich indenter used in the present work, $\varepsilon$ is equal to 0.75 .

In general, from indentation testing, the elastic modulus $(E)$ can be obtained by the following equations:

$$
\begin{aligned}
& E=\left(1-v^{2}\right)\left(\frac{1}{E^{*}}-\frac{1-v_{i}^{2}}{E_{i}}\right)^{-1}, \\
& E^{*}=\frac{\sqrt{\pi}}{2 \beta} \frac{S}{\sqrt{A_{\mathrm{c}}}},
\end{aligned}
$$

where $E^{*}$ is the effective modulus of the indenter-sample system and $E$ and $E_{i}$ are the elastic modulus of the sample and the indenter, respectively. $v$ and $v_{i}$ are Poisson ratios of the sample and the indenter, respectively, where $v$ is 0.07 and $v_{i}$ is $0.31 . \beta$ is a correction factor associated with the indenter shape, 1.034 for a Berkovich indenter.

According to Eqs. (1)-(4) and the instrumented indentation procedure, the results of the loading-unloading tests, as shown in Fig. 8, were converted into hardness values $(H)$ and elastic modulus $(E)$ for different coatings. 
Table 3 Potentiodynamic polarization tests of bare Al, Ni-P coating and $\mathrm{Ni}-\mathrm{P} / \mathrm{Ni}-\mathrm{Mo}-\mathrm{P}$ duplex coatings with different thicknesses of NiMo-P coating in $0.5 \mathrm{~mol} / \mathrm{L} \mathrm{H}_{2} \mathrm{SO}_{4}$ solution $\left(E_{\text {corr }}\right.$ : corrosion potential, $I_{\text {corr: }}$ corrosion density)

\begin{tabular}{lcc}
\hline Thickness of Ni-Mo-P coating $(\mu \mathrm{m})$ & $E_{\text {corr }}(\mathrm{V})$ & $I_{\text {corr }}\left(\mathrm{A} / \mathrm{cm}^{2}\right)$ \\
\hline Bare Al & -1.205 & $5.624 \times 10^{-4}$ \\
0 (Ni-P coating) & -0.113 & $7.385 \times 10^{-6}$ \\
4 & -0.126 & $3.285 \times 10^{-6}$ \\
7 & -0.086 & $1.526 \times 10^{-6}$ \\
10 & -0.098 & $2.332 \times 10^{-6}$ \\
13 & -0.430 & $2.929 \times 10^{-6}$ \\
17 & -0.478 & $8.560 \times 10^{-5}$ \\
\hline
\end{tabular}

Obviously, at the same depth (such as $1500 \mathrm{~nm}$ ), loads on the Ni-P coating and the duplex Ni-P/Ni-Mo-P coating were much higher than that of the $\mathrm{Al}$ substrate, which indicated that the Ni-P coating and duplex Ni-P/Ni-Mo-P coating were of high hardness and elastic modulus. As shown in Fig. 8b, the hardness of the Ni-P coating and the duplex coating was five times and nine times higher than that of the Al substrate, and the elastic modulus was also increased by 94 and $167 \%$, respectively. Obviously, the duplex Ni-P/Ni-Mo-P coating exhibited the highest $H$ and largest $E$ values, due to the co-deposition of Mo element and the compact microstructure [32].

In addition, as shown in Fig. 9, we found a jump point at the $900 \mathrm{~nm}$ penetration depth for the duplex Ni-P/Ni-Mo$\mathrm{P}$ coating, i.e., the slope of the curve reduced suddenly at the point, which indicated that this point was the interface between the Ni-P coating and the Ni-P-Mo coating. Apparently, the former portion of the curve belonged to the

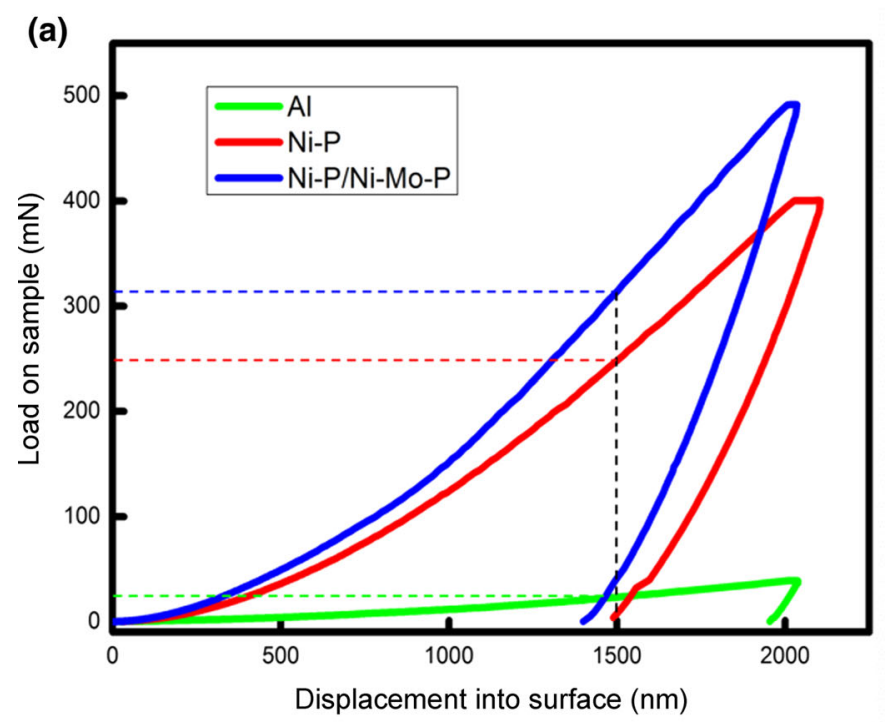

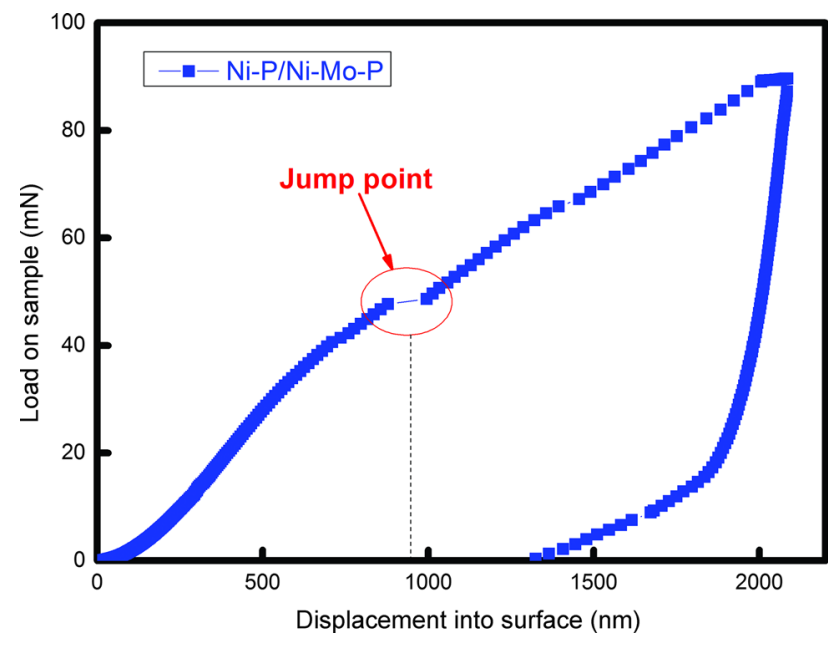

Fig. 9 Load-displacement curve showing jump point at interface between Ni-P coating and $\mathrm{Ni}-\mathrm{Mo}-\mathrm{P}$ coating of $\mathrm{Ni}-\mathrm{P} / \mathrm{Ni}-\mathrm{Mo}-\mathrm{P}$ duplex coating

top Ni-Mo-P coating with higher $H$ and larger $E$, and the latter was the transition Ni-P coating [33].

\section{Conclusions}

The duplex Ni-P/Ni-Mo-P coating was successfully synthesized by dual bath electroless deposition on the $\mathrm{Al}$ substrate. The following conclusions could be drawn:

(1) The duplex coating was of compact surface and favorable thickness homogeneity.

(2) The duplex coating without holes was obtained when the Ni-P coating served as a transition layer under a

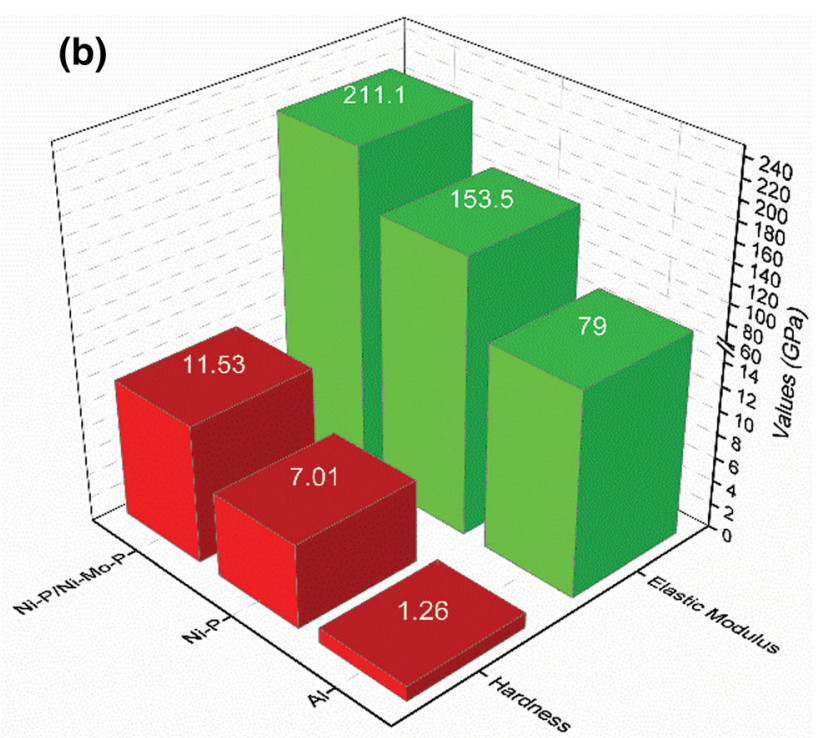

Fig. 8 Load-displacement curves a and fitted results of hardness and elastic modulus b of bare Al, Ni-P coating and Ni-P/Ni-Mo-P duplex coatings 
relative thin $\mathrm{Ni}-\mathrm{Mo}-\mathrm{P}$ coating, which was attributed to the proper surface state of the Ni-P coating.

(3) For a total $20 \mu \mathrm{m}$ coating thickness, the duplex coating with a $7 \mu \mathrm{m}$ of the $\mathrm{Ni}-\mathrm{Mo}-\mathrm{P}$ coating exhibited the best corrosion resistance in $0.5 \mathrm{~mol} / \mathrm{L}$ sulfuric acid, because of its compact surface and low porosity.

(4) Due to the co-deposition of Mo element, the hardness of the Ni-P coating and the duplex coating was five times and nine times higher than that of the $\mathrm{Al}$ substrate, and the elastic modulus was also increased by 94 and $167 \%$, respectively.

(5) The synthesis process of this duplex coating with advantages, such as simple, low cost, environmental friendly, desired controllability and repeatability, is suitable to industrial production, thereby expanding the applications of $\mathrm{Al}$ and its alloys in the fields of machine manufacture and corrosion environment.

Acknowledgements This work was supported financially by the National Natural Science Foundation of China (No. 11174227), the National R\&D Infrastructure and Facility Development Program of China (No. 2005DKA10400), the Scientific Research Project of Liaoning Province Department of Education (No. L2010396) and the Chinese Universities Scientific Fund.

\section{References}

[1] Y.B. Unigovski, A. Grinberg, E. Gerafi, E.M. Gutman, Surf. Coat. Technol. 232, 695 (2013)

[2] W.S. Miller, L. Zhuang, J. Bottema, A.J. Wittebrood, P. De Smet, A. Haszler, A. Vieregge, Mater. Sci. Eng., A 280, 37 (2000)

[3] W. Qin, J. Coat. Technol. Res. 8, 135 (2010)

[4] Y.S. Huang, Adv. Mater. Res. 189-193, 265 (2011)

[5] A.E. Fetohi, R.M.A. Hameed, K.M. El-Khatib, J. Ind. Eng. Chem. 30, 239 (2015)

[6] N. Nagata, T. Kanadani, K. Nakagawa, M. Fukuhara, K. Horikawa, K. Murakami, M. Hino, J. Jpn. Inst. Met. 79, 151 (2015)

[7] N. Nagata, T. Kanadani, K. Nakagawa, M. Fukuhara, K. Horikawa, K. Murakami, M. Hino, J. Jpn. Inst. Met. 79, 146 (2015)
[8] L.W. Ren, Z. Wang, M.M. Meng, H. Tian, H.J. Yang, J.W. Qiao, J. Non-Cryst. Solids 430, 115 (2015)

[9] A.E. Fetohi, R.M.A. Hameed, K.M. El-Khatib, E.R. Souaya, Int. J. Hydrogen Energy 37, 10807 (2012)

[10] M.L. Wang, Z.G. Yang, C. Zhang, D.L. Liu, Trans Nonferrous Met. Soc. 23, 3629 (2013)

[11] X. Shu, Y. Wang, X. Lu, C. Liu, W. Gao, Surf. Coat. Technol. 276, 195 (2015)

[12] E. Valova, S. Armyanov, G. Hristova, T. Vassilev, O. Steenhaut, J. Dille, A. Hubin, I. Vandendael, Surf. Coat. Technol. 304, 468 (2016)

[13] X.L. Wang, Y.X. Zheng, M.L. Jia, L.S. Yuan, C. Peng, W.H. Yang, Int. J. Hydrogen Energy 41, 8449 (2016)

[14] J. Li, D. Wang, H. Cai, A. Wang, J. Zhang, Surf. Coat. Technol. 279, 9 (2015)

[15] G. Lu, G. Zangari, J. Electrochem. Soc. 150, C777 (2003)

[16] Y.H. Chou, C.Y. Bai, M.D. Ger, C.L. Chao, S.J. Lee, C.Y. Lee, in Proceedings of the 35th International MATADOR Conference, Springer, London, United Kingdom, 2007, pp. 21-24

[17] A.E. Fetohi, R.M.A. Hameed, K.M. El-Khatib, J. Power Sources 240, 58 (2013)

[18] D.L. Liu, Z.G. Yang, C. Zhang, Mater. Sci. Eng., B 166, 67 (2010)

[19] R.C. Agarwala, V. Agarwala, Sadhana 28, 475 (2003)

[20] H. Liu, Y.Y. Lv, Z. Liu, H. Liu, G.E. Thompson, Tribol. Int. 103, 343 (2016)

[21] V.E. Selvi, P. Chatterji, S. Subramanian, J.N. Balaraju, Surf. Coat. Technol. 240, 103 (2014)

[22] C. Subramanian, K. Palaniradja, Int. J. Metall. Eng. 4, 25 (2015)

[23] Y. Wang, X. Shu, S. Wei, C. Liu, W. Gao, R.A. Shakoor, R. Kahraman, J. Alloys Compd. 630, 189 (2015)

[24] J. Sudagar, J. Lian, W. Sha, J. Alloys Compd. 571, 183 (2013)

[25] S. Sun, G.S. Song, Z. Ma, Surf. Technol. 45, 49 (2016). (In Chinese)

[26] L.M. Abrantes, A. Fundo, G. Jin, J. Mater. Chem. 11, 201 (2001)

[27] X.B. Xi, H. Miao, R.H. Zhang, J. Cheng, Surf. Coat. Technol. 297, 27 (2016)

[28] J.N. Balaraju, N. Raman, N.T. Manikandanath, Trans. Inst. Met. Finish. 92, 169 (2013)

[29] H.M. Lee, H. Chae, C.K. Kim, Korean J. Chem. Eng. 29, 1259 (2012)

[30] J.C. Hsu, K.L. Lin, Thin Solid Films 471, 186 (2005)

[31] M. Sribalaji, O.S. Asiq Rahman, T. Laha, A.K. Keshri, Mater. Chem. Phys. 177, 220 (2016)

[32] A.S. Hamada, P. Sahu, D.A. Porter, Appl. Surf. Sci. 356, 1 (2015)

[33] P. Wiecinski, J. Smolik, H. Garbacz, J. Bonarski, A. Mazurkiewicz, K.J. Kurzydłowski, Surf. Coat. Technol. 309, 709 (2017) 